\title{
AN INVESTIGATION INTO THE EFFECTS OF THE APPLICATION OF TQM, TPM, AND JIT ON PERFORMANCE OF INDUSTRY IN BAHRAIN
}

\author{
B. Al Mannai, S.M.A. Suliman \\ Department of Mechanical Engineering \\ University of Bahrain, Isa Town, Kingdom of Bahrain \\ Y. Al Alawai \\ Bahrain Institute for Political Development \\ Um Al Hassam, Kingdom of Bahrain
}

\begin{abstract}
Despite the importance of quality management systems in the manufacturing industry, few studies are directed to gauge their comparative effectiveness whether in Bahrain or worldwide. In addition, there has been a limited examination of the common and unique practices associated with these programs worldwide, but none for Bahrain. Accordingly, the main purpose of this paper is to study and evaluate the effects of the application of Total Quality Management (TQM), Total Productive Maintenance (TPM), and Just in Time (JIT) on the performance of industry in Bahrain. The paper presents the common, unique success factors, and the performance indicators associated with each program. In addition, the paper examines the relationships between these quality programs initiatives and their effects on the industry in Bahrain. The paper concludes that the implementation of TQM, TPM, and JIT has positive effect, and that the TQM quality program is the most effective and beneficial program to improve the performance of industry in Bahrain.
\end{abstract}

Key words: Total Quality Management; Total Productive Management; Just in Time; Success factors; Performance indicators.

Cite this Article: B. Al Mannai, S.M.A. Suliman and Y. Al Alawai, An Investigation into the Effects of the Application of TQM, TPM and JIT on Performance of Industry in Bahrain, International Journal of Industrial Engineering Research and Development, 8(1), 2017, pp. 9-19. https://iaeme.com/Home/issue/IJIERD?Volume=8\&Issue=1

\section{INTRODUCTION}

In response to the national and global market challenges in the manufacturing industries worldwide, quality and process improvements were found to be the most effective solutions (Bayazit, 2003). According to Bayazit (2003), there is a huge amount of literature published on the performance improvements and effectiveness achieved from the implementation of quality initiative and programs. The most common quality programs implemented are TQM, TPM, and JIT (Reeda et al., 2000). However, the majority of research and empirical case studies, in the literature, on the topics of quality programs and implementation effectiveness assess TQM, TPM, and JIT programs in isolation (Cua et al., 2001). In 
addition, there has been examination of the common and unique practices associated with these programs worldwide, but none for Bahrain.

Bahrain manufacturing industry is composed of various sectors ranging from heavy industry to light industry. The main manufacturing plants are associated with oil refinery, oil derivatives, and Aluminum. In addition to these, other types of industries such as engineering, food processing, and power generation are playing an important role in the economy of the island. Due to the huge size of operations, revenue and number of employees, these companies are expected to adopt the latest technology and quality programs available.

Accordingly, the purpose of this work is to measure the effectiveness of these quality programs in Bahrain, and examine the relationship between the adoption of TQM, TPM, and JIT on the industry performance in Bahrain.

\section{LITERATURE REVIEW}

The literature review presented in this paper is directed towards the empirical part of studies conducted to compare TQM, TPM, JIT quality programs, and to evaluate their effectiveness.

TQM is described as a manufacturing program aimed at continuously improving and sustaining quality products and processes through the involvement of management, workforce, suppliers, and customers to meet or exceed customer expectations (Kristy, 2001). Furthermore, Munziu (2013) characterize TQM as an action plan to produce and deliver commodities, which are consistent with customers' needs, enhanced quality, and less cost than competitors; through the participation of all employees under top management leadership.

In the TQM case studies literature an empirical model is developed to evaluate the TQM practices Small and Medium Enterprises (SME) electronic industry in Malaysia based on 59 companies' questionnaire responses (out of 248 companies being addressed). A significant difference is revealed between small and large companies' quality practices. Management leadership, continuous improvement system, and education and training among the top factors for successful implementation by large companies compared with (SEM's). However, supplier quality management is the least implemented criterion by both large and SME companies (Quek and Shari, 2003).

Moreover, Zhang (2000) developed a model of quality management methods (QMMs). The model had eighty three QMMs (distinguishable methods used for quality management), and they are categorized by eleven primary TQM elements: leadership; supplier quality management; vision and plan statement; evaluation; process control and improvement; product design; quality system improvement; employee participation; recognition and reward; education and training; and customer focus.

Selected companies from Netherlands, known for quality management, showed that QMMs had positive effects on product quality, and TQM could lead not only to improvement in product quality, but also to improvement in strategic business performance, process quality, supplier quality management, customer focus and human resource management. The study showed that ISO 9000 had a much lower impact on business performance than TQM.

However, Mann and Kehoe (1994 and 1995) created a model that can assist organizations in selecting and targeting quality activities to address their specific problems and to identify relationships between the characteristics of their organizations, quality improvement activities, and business performance indicators. The model is a business performance classification system that categorized business performance into strategic and operational, and for each category measures are formulated to assess the effects of quality activities. Among the measures formulated to assess the effects of quality activities on strategic performance are market share changes in customer base, and sales turnover. Whereas, some of the measures used for assessment of operational performance are vendor performance, supplier communications, work in progress, lead time, product quality, quality cost, employee morale and communication, customer communication and quality reputation. The investigation identified that the five 
most beneficial quality activities are TQM, ISO 9000, delegated teams, quality awareness program, and supplier improvement activities (Mann and Kehoe, 1993).

TPM is defined by Nakajima (1988) as a maintenance system that covers the entire life of equipment in every division including: planning, manufacturing, and maintenance. In addition, it describes a synergistic relationship among all organizational functions to ensure continuous improvement of product quality, operational efficiency, capacity assurance, and safety. (chana et al., 2005) The benefits of implementing TPM are to maximize equipment effectiveness and efficiency, enhance equipment technology, and provide a comprehensive company-wide approach to maintenance management (McKone et al., 1999 and 2001). The most commonly cited practices of TPM are autonomous maintenance and planned maintenance, equipment technology emphasis, committed leadership, strategic planning, cross functional training, and employee involvement. (Nakajima, 1988; Takahashi, 1990; Mckone et al; 1999).

Ahuja et al. (2008) conducted an industrial survey on Indian med-large manufacturing industry, to evaluate the contributions of TPM initiatives towards realizing manufacturing performance improvements. Three key TPM success factors (top management leadership and involvement, traditional maintenance initiatives, and TQM implementation initiatives) and seven manufacturing performance parameters (organizational achievements, productivity, quality, cost, delivery, safety, and morale) had been identified as significant for analyzing the impact of TPM initiatives for achieving manufacturing performance improvements.

The study revealed that the TPM initiatives are more influential in improving manufacturing performance than the traditional maintenance practices. in addition, the top management can effectively contribute to performance improvement by providing effective structure for TPM implementation, providing effective reward and recognition mechanisms, and providing resources for managing change in the organization. It is concluded that TPM initiatives are essential for meeting the challenges of highly competitive environments.

Furthermore, Miyake and Enkawa (1999) carried out a comparative analysis of the total quality control (TQC) and total productive maintenance (TPM) paradigms. It focused on examining the relationship between TQC and TPM, and how the two paradigms could be complementary to each other. The study highlighted the promising potential of exploiting the strengths that are intrinsic to these two subject paradigms for fostering the new competencies that needed by manufacturing firms. In addition, they advocated that such a manufacturing strategy could be developed by the cumulative stepwise and consistent embedding of performance improvement mechanisms derived from each of the subject paradigms under the framework of unfolding 'strategic staircases'.

JIT is described as a manufacturing program with the primary goal of continuously reducing and ultimately eliminating all forms of waste, through JIT production and involvement of the work force. The nine practices that are frequently cited as JIT practices are: set-up time reduction, pull system production, JIT delivery by supplier, functional equipment layout, daily schedule adherence, committed leadership, strategic planning, cross-functional training, and employee involvement (Cua et. al., 2001).

Some of these practices are also commonly cited as part of a TQM program: cross functional product design, process management, supplier quality management, customer involvement, information and feedback, committed leadership, strategic planning, cross-functional training, and employee involvement (Saraph et al, 1989; Flynn et al., 1995; Samson and Treziovski, 1999).

The above literature review reveals five common practices among TQM, TPM, and JIT. They are committed leadership, strategic planning, cross-functional training, employee involvement, and information /measurement feedback. In addition, it demonstrates that there is direct relationship between the three programs.

Now that the common practices between TQM, TPM, and JIT have been reviewed, and the fact that nothing has been written on these programs effectiveness on Bahrain industries performance in the 
literature, the aim of this paper is to assess the degree of TQM, TPM, and JIT implementation on Bahrain industries performance.

\section{METHODOLOGY}

The study was based on a survey combing both qualitative and quantitative method. The two methods were used in forming the survey semi-structured interviews. Two sets of questionnaires were developed, a set targeting the operational level and a second targeting the strategic level. The operational level questionnaire includes 41 statements, addressed to the operation workforce, to identify the extent of TQM, TPM, and JIT implementation in Bahrain industry. The strategic level questionnaire includes 56 statements, addressed to the top management, to extract managerial details on TQM, TPM, and JIT implementation and their effect on the organization performance.

Based on Bahrain Ministry of Industry and Commerce classification (large and medium size organizations) was used to enable better sample selection representation. Accordingly, the manufacturing organizations selected for this research study were limited to the organizations that have a workforce not less than 50 employees, and an annual turnover over 2.5 million US Dollars. A total of 39 organizations resulted from the database met the selection criteria, and 15 positive responses were received, representing $38.5 \%$ response rate.

\section{FINDINGS AND DISCUSSION}

The results of each quality program are presented in isolation from the other, the discussed in an inclusive form to give a clear overall picture of the findings.

\subsection{TQM Implementation Results}

At the operational level, thirteen measurement indicators were used, whereas, at the strategic level eleven measurement indicators were used. The indicators were grouped into ten groups, where each group represents certain success factor. Further, a measurement indicator may contribute to more than one success factor. The results of TQM implementation obtained from the operational and strategic level questionnaires are shown in Table 1.

Table 1 Degree of TQM success factors implementation

\begin{tabular}{|l|c|}
\hline \multicolumn{1}{|c|}{ Success Factor } & Implementation (\%) \\
\hline Leadership & 100 \\
\hline Quality Procedures & 100 \\
\hline Focused Improvement & 100 \\
\hline Supplier Quality & 91 \\
\hline Customer Satisfaction & 90 \\
\hline Employee Participation & 89 \\
\hline Information and Feedback & 89 \\
\hline Employee Satisfaction & 88 \\
\hline Employee Training & 88 \\
\hline Quality Certification & 86 \\
\hline Average Implementation \% & 92 \\
\hline
\end{tabular}


Table 1 shows that out of the ten TQM success factors implemented, three success factors (Leadership, Quality Procedures, and Focused Improvement) scored the highest percentage (100\%). The results analysis indicated that all the responded companies have long term quality improvement programs, and that the top management is personally involved in the quality improvement projects. In addition, it was found that all the respondents had quality documentation available and controlled. Moreover, the respondents understood the nature of their quality problems and have well established quality information measures.

The Supplier Quality and Customer Satisfaction success factors obtained scores of $91 \%$ and $90 \%$ respectively. The Supplier Quality success factor was assessed through the degree the organization audits its suppliers, to ensure its suppliers apply and maintain quality standards. While, the Customer Satisfaction success factor was assessed through the degree the organization has close customer relationship, applies different strategies to receive internal and external customer feedback, and deals with customer complaints effectively and promptly.

The Employee Participation and Information and Feedback success factors scored the same percentage of $89 \%$. The Employee Participation success factor was assessed through the degree the organization encourage their employees to participate in solving and improving quality related problems. While, the Information and Feedback success factor was assessed through the degree the organization possesses quality policy and manuals, analyses its statistical control process results, exhibits its performance measures results (operational, strategic, and financial), and utilizes quality data for supervisors and managerial evaluation.

The Employee Satisfaction and Employee Training success factors each scored 89\%. The Employee Satisfaction success factor was assessed through the degree the organization sets realistic goals, resolves employee complaints effectively, and conducts various employee satisfactions assessment techniques. While, the Employee Training success factor was assessed through the degree the organization applies individual, multiple, and cross-functional training plans.

The Quality Certification success factor, on the other hand, was found to be the least TQM success factor implemented (86\%). It was assessed through the degree the organization is assessed through a third party and is ISO certification.

Accordingly, the overall average implementation of TQM program in the industrial and manufacturing sector in Bahrain represents $92 \%$.

\subsection{TPM Implementation Results}

At the operational level, nineteen measurement indicators were used, whereas, at the strategic level nine measurement indicators were used. The indicators were grouped into seven groups, where each group represents certain success factor. Further, a measurement indicator may contribute to more than one success factor. The results of TPM implementation obtained from the operational and strategic level questionnaires are shown in Table 2.

Table 2 Degree of TPM success factors implementation

\begin{tabular}{|l|c|}
\hline \multicolumn{1}{|c|}{ Success Factor } & Implementation (\%) \\
\hline Autonomous Maintenance. & 94 \\
\hline Planned Maintenance. & 91 \\
\hline Focused Improvements & 88 \\
\hline Employee Training & 88 \\
\hline Information and Feedback & 78 \\
\hline Employee Participation & 73 \\
\hline Technology Focus & 59 \\
\hline Average Implementation \% & 82 \\
\hline
\end{tabular}


The Autonomous Maintenance success factor was implemented in $94 \%$ of the responded companies, as can be seen in Table 2. This success factor was assessed through the degree the organization has dedicated maintenance teams and support machine operators to perform their own Preventative Maintenance.

The Planned Maintenance success factor scored 91\%. It was assessed through the degree the organization conducts the Predictive Maintenance plans, conducts Preventative Maintenance plans, and continuously updates the Predictive and Preventative Maintenance programs.

The Focused Improvements and Employee Training success factors each scored $88 \%$. The Focused Improvements success factor was assessed through the degree the organization adopts maintenance initiatives to track root cause performance losses, identifies equipment bottlenecks, applies Preventative and predictive Maintenance, and focuses on work environment improvements. While, the Employee Training success factor was assessed through the degree the organization provides maintenance training on maintenance programs, such as Zero Breakdown, Computerized Maintenance Management package, and Overall Equipment Effectiveness, deploys maintenance initiatives to support employee skills and efforts evaluation, and applies workplace housekeeping.

The Information and Feedback success factor scored $78 \%$. The factor was assessed through the degree the organization displays breakdown frequencies on the shop floor, conducts breakdown diagnosis evaluation, and standardizes maintenance documentation and procedures.

The Employee Participation success factor scored 73\%. It was assessed through the degree the organization encourages the operator involvement in maintenance initiatives and breakdown diagnoses.

The least TPM success factor implemented, on the other hand, was found to be Technology Focus. Analysis of the results of the technologies revealed that $59 \%$ of the respondents use lubricating oil, vibration, and ultrasonic technologies.

Accordingly, the overall implementation of TPM program in the industrial and manufacturing sector in Bahrain represents $82 \%$.

\subsection{JIT Implementation Results}

At the operational level, twelve measurement indicators were used, whereas, at the strategic level five measurement indicators were used. The indicators were grouped into four groups, where each group represents certain success factor. Further, a measurement indicator may contribute to more than one success factor. The results of JIT implementation obtained from the operational and strategic level questionnaires are shown in Table 3.

Table 3 Degree of JIT success factors implementation

\begin{tabular}{|l|c|}
\hline \multicolumn{1}{|c|}{ Success Factor } & Implementation (\%) \\
\hline Supplier Quality & 89 \\
\hline Customer Satisfaction & 87 \\
\hline Focused Improvements & 76 \\
\hline Employee Satisfaction & 67 \\
\hline Average Implementation \% & 80 \\
\hline
\end{tabular}

The Supplier Quality success factor was implemented in $89 \%$ of the responded companies, as can be seen in Table 3. It was assessed through the degree the organization deals with few suppliers that are ISO certified, capable to deliver in short notice, part of the product development team, and committed to long term contracts.

The Customer Satisfaction success factor scored $87 \%$. The factor was assessed through the degree the organization applies different strategies to improve response time, enhances product availability on demand internal customer (employee) feedback, and deals with customer complaints effectively 
The focused Improvements success factors scored $76 \%$. This success factor was assessed through the degree the organization conducts setup time reduction training courses, has low in-progress inventory, early problem identification procedure in the shop floor, and degree of effort spent to lower operation setup time.

The least JIT success factors implemented was found to be Employee Satisfaction, scoring 67\%. The Employee Satisfaction success factor was assessed through the degree the organization rewards their operators for production and quality improvements, and the degree of authority to stop production when a quality problem is identified.

Accordingly, the overall implementation of JIT program in the industrial and manufacturing sector in Bahrain represents $80 \%$.

\subsection{TQM, TPM, and JIT Implementation Effects on Organization Performance}

This part of analysis involves presenting the overall TQM, TPM, and JIT implementation results versus the overall implementation effect on Bahrain industrial performance, which is the focus of this survey. The strategic questionnaire included a dedicated section to establish the effects of TQM, TPM, and JIT implementation on performance of the Bahraini industry. The operational questionnaire did not include such section, due to the fact that the assessment of the operational, financial, and managerial performance effects can be adequately identified by the senior management.

Thirty one performance improvement indicators (PIIs) were used to assess the implementation effect on performance of the organization. The indicators were grouped into six dimensions, where each group represents certain performance dimension. Further, a performance indicator may contribute to more than one performance dimension. The results of the quality programs implementation effect on the overall organization performance obtained from the strategic level are shown in Figure 1.

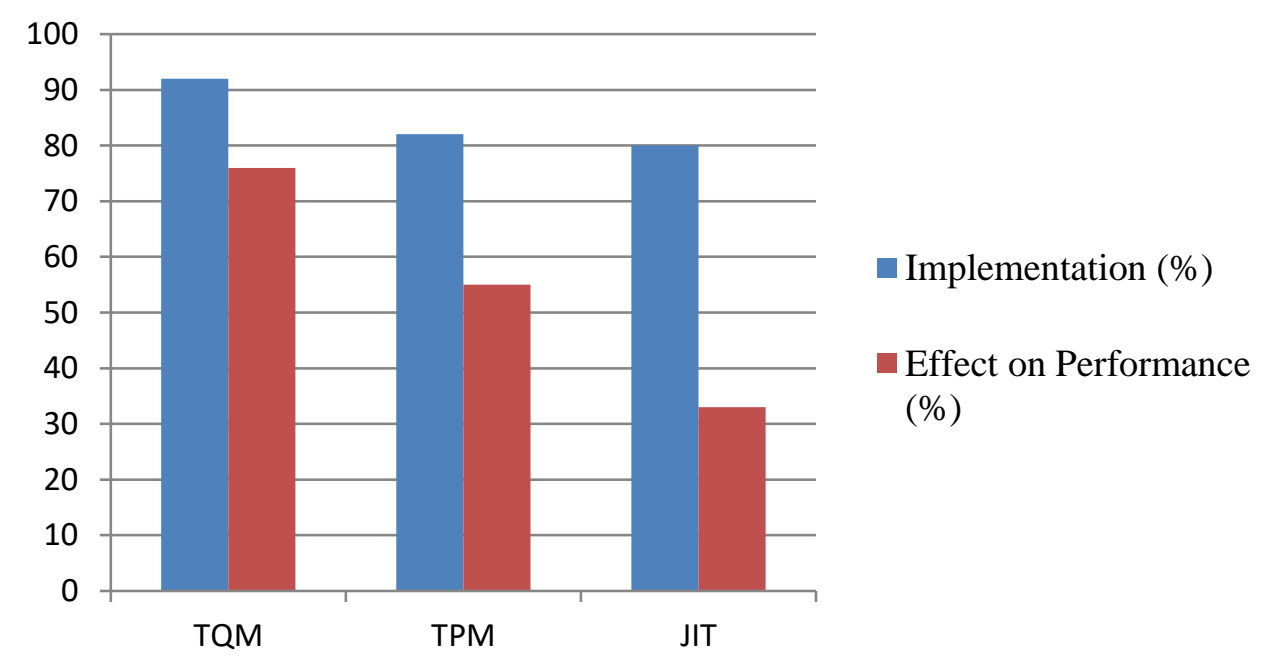

Figure 1 Overall effects of TQM, TPM, and JIT implementation on performance improvement

From Figure 1 it can be concluded that TQM quality program implementation had the highest positive effect on Bahrain industrial performance. TQM implementation over the entire industrial organizations surveyed in Bahrain was found to be $92 \%$, while this implementation effort resulted in an overall improvement of $76 \%$ in organization performance. The results analyses show that TPM quality program implementation (82\%) had moderate improvement effect on organization performance $(55 \%)$.

However, what was not expected the amount of effort exerted on JIT implementation (80\%), resulted in relatively lesser reflection on performance improvement $(33 \%)$. The following analysis describes in details the overall performance improvement indicators that were affected by each quality program implementation. 
An Investigation into the Effects of the Application of TQM, TPM and JIT on Performance of Industry in Bahrain

\subsubsection{TQM Implementation Effect on Organization Performance}

The results of the TQM implementation effect on the overall organization performance are shown in Figure 2.

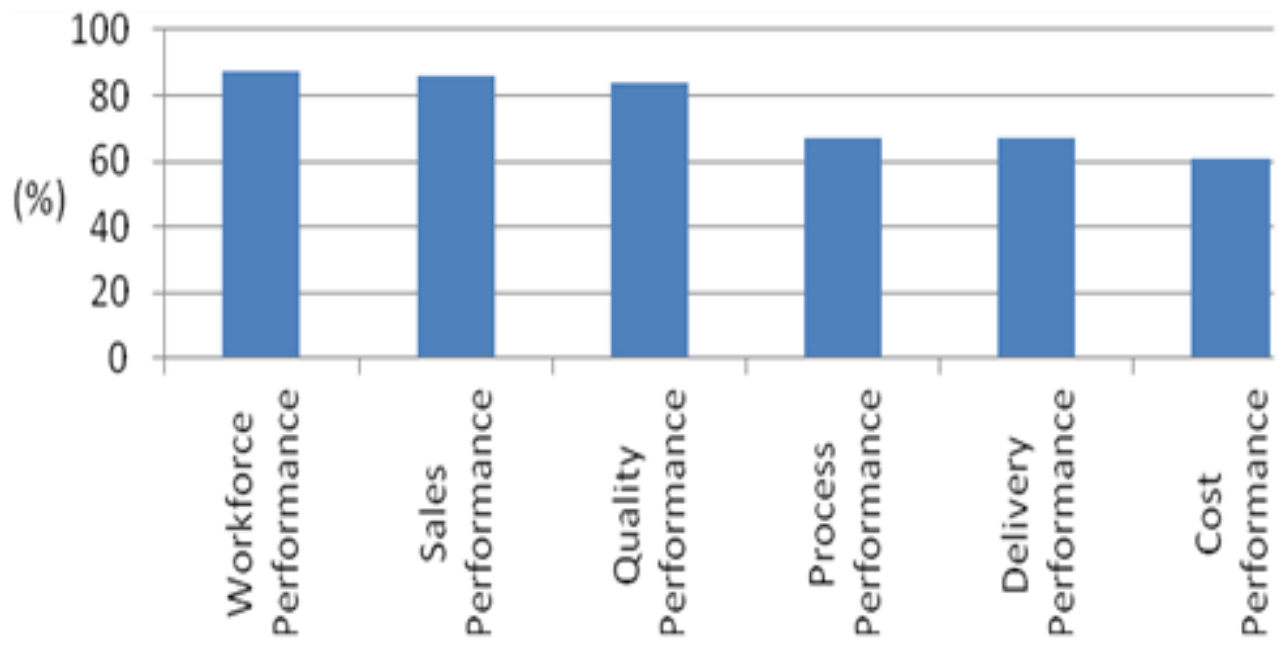

Figure 2 Overall effects of TQM implementation on performance improvement dimensions

The highest positive effect of TQM implementation on organization performance was found to be on workforce performance $(87 \%)$. The respondents indicated that TQM implementation had significant impact on the following performance improvement indicators (within the workforce performance dimension): workforce professionalism enhancement, workforce multi-skills development, empowerment enrichment, and greater employee satisfaction.

In addition, there was clear impact on sales performance $(86 \%)$ and quality performance $(84 \%)$. The respondents indicated that TQM implementation had significant impact on the following performance improvement indicators (within the sales performance dimension): organization image improvement, and new customer base establishment. While, similar impact was noticed on the following performance improvement indicators (within the quality performance dimension): product performance and reliability improvement, employees' quality awareness and appreciation improvement, and increasing internal customer satisfaction rate.

On the other hand, the lowest positive effect of TQM implementation on organization performance was found to be on cost reduction (61\%). The respondents indicated that TQM implementation had positive impact on the following performance improvement indicators (within the cost performance dimension): overhead cost, and material cost reduction.

\subsubsection{TPM Implementation Effect on Organization Performance}

The results of the TPM implementation effect on the overall organization performance are shown in Figure 3. 


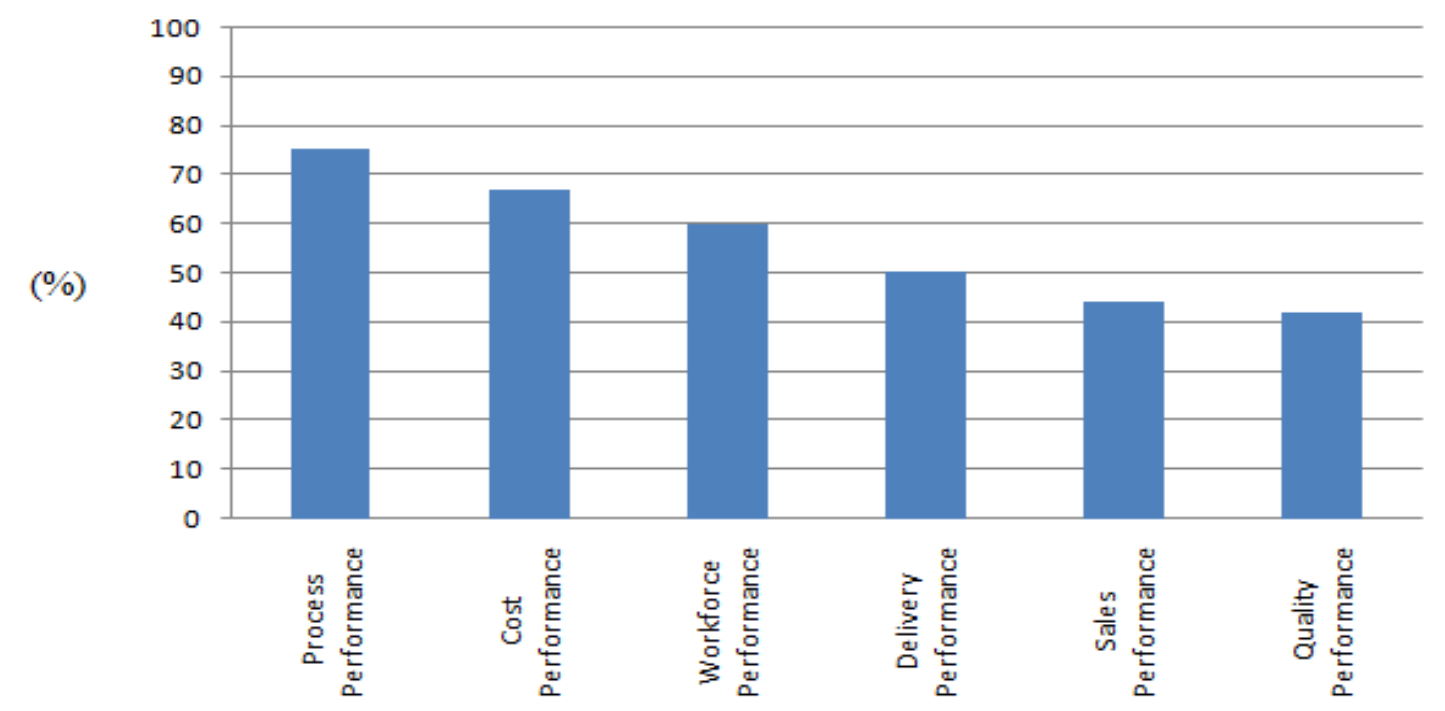

Figure 3 Overall effects of TPM implementation on performance improvement dimensions

The highest positive effect of TPM implementation on organization performance was found to be on process performance $(75 \%)$. The respondents indicated that TPM implementation had significant impact on the following performance improvement indicators (within the process performance dimension): reducing unplanned downtime, improving equipment reliability, and improving process capabilities. Furthermore, the cost performance dimension ranked second in place $(67 \%)$, and the respondents indicated that TPM implementation had positive impact on the following performance improvement indicators (within the cost performance dimension): reducing maintenance cost and reducing unit cost.

The lowest positive effect of TPM implementation on organization performance, however, was found to be on quality improvement (42\%). The respondents indicated that TPM implementation had favorable impact on the following performance improvement indicators (within the quality performance dimension): improving corrective action, and improving product defect rate.

\subsubsection{JIT implementation effect on organization performance}

The results of the JIT implementation effect on the overall organization performance are shown in Figure 4.

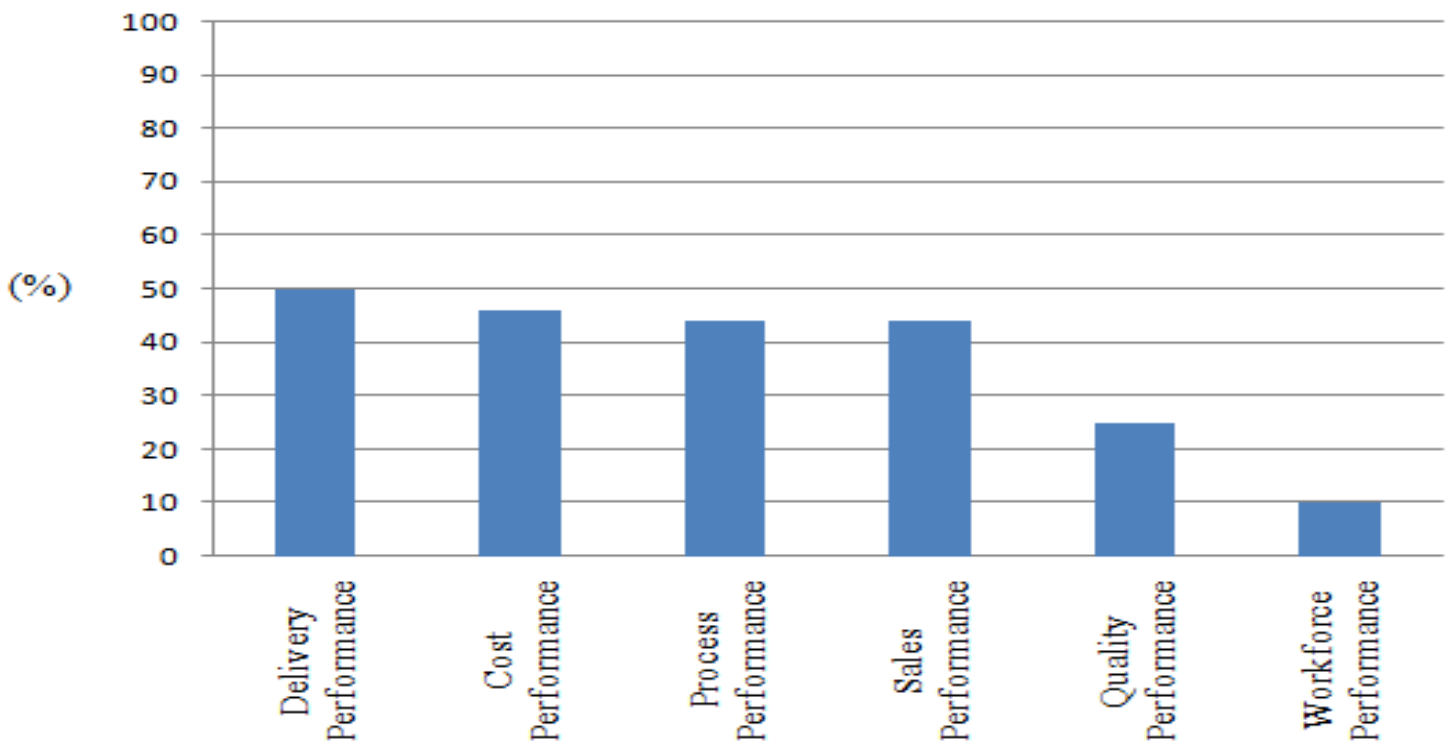

Figure 4 Overall effects of JIT implementation on performance improvement dimensions 
The highest positive effect of JIT implementation on organization performance was found to be on delivery performance (50\%). The respondents indicated that JIT implementation had significant impact on the following performance improvement indicators (within the delivery performance dimension): increasing delivery speed and improving after sales service. In addition, the cost performance dimension ranked second in place (46\%), and the respondents indicated that TPM implementation had positive impact on the following performance improvement indicators (within the cost performance dimension): reducing inventory level and manpower.

The lowest positive effect of JIT implementation on organization performance was found to be on workforce performance improvement (10\%). The respondents indicated that JIT implementation had positive impact on the following performance improvement indicator (within the workforce performance dimension): improving employee professionalism.

\section{CONCLUSION}

The aim of this paper was to study and evaluate the effects of the application of Total Quality Management (TQM), Total Productive Maintenance (TPM), and Just in Time (JIT) on the performance of industry in Bahrain. Based on the assessment of the operational and strategic success factors used for TQM, TPM and JIT, it was found that the degree of TQM implementation in Bahrain was 92\%, that of TPM implementation was $82 \%$ and that of JIT implementation was $80 \%$.

Furthermore, the study showed that TQM quality program had the highest positive effect on Bahrain industrial performance. With an overall of $92 \%$ implementation, TQM resulted in a $76 \%$ improvement in organization performance. TPM with an implementation of $82 \%$ had a moderate effect on the organization performance, improving it by 55\%. However, with an implementation of $80 \%$, JIT had a relatively low effect on organization performance, only improving it by 33\%. The study also revealed the effects of the TQM, TPM and JIT implementations on distinct performance improvement indicators. TQM implementations resulted in greatly improving the workforce performance, sales performance and quality performance $(87 \%, 86 \%$, and $84 \%$, respectively) and had the least effect on cost reduction (61\%) of the organizations where it was implemented. The TPM implementations had the most positive effect on process performance $(75 \%)$, closely trailed by improvements in cost performance $(67 \%)$ and had the least effect on quality improvement (42\%). The JIT implementation had the highest effects on delivery and cost performance (50\% and $46 \%$ respectively) and had the lowest effect on the workforce performance improvement (10\%).

\section{AKNOWLEDGEMENT}

This material was based on research supported by the Deanship of Scientific Research [grant No. 2010/21], University of Bahrain.

\section{REFERENCES}

[1] Hebeish, A. and El-Rafie, M. H. American Dyestuff Reporter,79 (7), 1990, pp. 34.

[2] Maganioti, A.E., Chrissanthi, H.D., Charalabos, P.C., Andreas, R.D., George, P.N. and Christos, C.N. Cointegration of Event-Related Potential (ERP) Signals in Experiments with Different Electromagnetic Field (EMF) Conditions. Health, 2, 2010, pp. 400-406.

[3] Ahuja et al., 2008. An evaluation of TPM initiatives in Indian industry for enhanced manufacturing performance. International Journal of Quality and Reliability Management, Vol. 25 No. 2, 147-172.

[4] Flynn, B.B., Sakakibara, S., Schroeder, R., 1995. Relationship between JIT and TQM: practices and performance. Academy of Management Journal, Vol. 38 (5), 1325-1360.

[5] Cua, K., McKone, K., and Schroeder, R., 2001. Relationships between implementation of TQM, JIT, and TPM and manufacturing performance. Journal of Operations Management, Vol. 19, 675-694. 
[6] McKone, K., Schroeder, R., Cua, K., 1999. Total Productive Maintenance: a contextual view. Journal of Operations Management, Vol. 17 (2), 123-144.

[7] McKone, K., Schroeder, R., Cua, K., 2001. The impact of Total Productive Maintenance practices on manufacturing performance. Journal of Operations Management, Vol. 19 (1), 39-58.

[8] Nakajima, S., 1988. Introduction to TPM. Productivity Press, Cambridge, MA.

[9] Bayazit, O., 2003. Case Study: total quality management (TQM) practices in Turkish manufacturing organizations. The TQM magazine, Vol. 15 (5), 345-350.

[10] Takahashi, Y., Osada, T., 1990. TPM: Total Productive Maintenance. Asian Productivity Organization, Tokyo, Japan.

[11] Samson, D., Terziovski, M., 1999. The relationship between Total Quality Management practices and operational performance. Journal of Operations Management, Vol. 17 (4), 393-409.

[12] Saraph, J., Benson, P., Schroeder, R., 1989. An instrument for measuring the critical factors of quality management. Decision Sciences, Vol. 20, 810-829.

[13] Miyake, D. and Enkawa, T., 1999. Matching the promotion of total quality control and total productive maintenance: an emerging pattern for the nurturing of well-balanced manufactures. Total Quality Management, Vol. 10 (2), 243-269.

[14] Zhang, Z., 2000. Developing a model of quality management methods and evaluating their effects on business performance. Total Quality Management, Vol. 11 (1), 129-137.

[15] Mann, R. and Kehoe, D., 1994. An evaluation of the effects of quality improvement activities on business performance. International Journal of Quality and Reliability Management, Vol. 11, 29- 44.

[16] Mann, R. and Kehoe, D., 1995. Factors affecting the implementation and success of TQM. International Journal of Quality and Reliability Management, Vol. 12, 11-23.

[17] Munizu, M., 2013. The impact of total quality management practices towards competitive advantage and organizational performance: case of fishery industry in South Sulawesi Province of Indonesia. Pakistan Journal of Commerce and Social Sciences, Vol. 7 (1), 184-197.

[18] Reeda, R., Lemakb, D., and Meroc, N., 2000. Total quality management and sustainable competitive advantage. Journal of Quality Management, Vol. 5, 5-26.

[19] Chana, F., Laub H., Ipc, R., Chana H., and Konga, S., 2005. Implementation of total productive maintenance: A case study. International Journal of Production Economics, Vol. 95 (1), 71-94.

[20] Quek, E., and Shari, M., 2003. A survey of TQM in the Malaysian electrical and electronic Industry. Total quality management, Vol. 14(1), 63-77.

[21] Vasantharayalu and Dr. Surajit Pal, An Empirical Study of Total Quality Management (TQM) Practices on Operational Performance of Indian Manufacturing and Service Firms. International Journal of Management, 7(6), 2016, pp. 192-202.

[22] B. Al Mannai, S. Suliman and Y. Al Alawai, TQM Implementation Effect on Bahrain Industrial Performance, International Journal of Industrial Engineering Research and Development, 7(2), 2016, pp. $75-81$. 